\title{
СПЕЦИАЛЬНЫЕ НАЛОГОВЫЕ РЕЖИМЫ В РАЗВИТИИ МАЛОГО И СРЕДНЕГО БИЗНЕСА
}

\author{
(c) 2018 Чотчаева Мадина Зулкарнаевна \\ кандидат экономических наук, доцент, доцент кафедры «Экономическая теория» \\ Северо-Кавказская государственная гуманитарно-технологическая академия \\ 369000, г. Черкесск, ул. Ставропольская, д. 36. \\ E-mail:madinach@mail.ru
}

В статье рассмотрены специальные налоговые режимы, установленные для малого и среднего бизнеса в соответствии с налоговым законодательством РФ. Предложены направления налоговой политики по повышению эффективности применения специальных налоговых режимов субъектами малого и среднего бизнеса.

Ключевые слова: специальные налоговые режимы, малый и средний бизнес, система налогообложения для сельскохозяйственных товаропроизводителей, упрощенная система налогообложения, единый налог на вмененный доход для отдельных видов деятельности, патентная система налогообложения.

В настоящее время одним их приоритетных направлений экономической политики является реформирование налоговой системы страны, которая обеспечивала бы не только расширение налоговых источников и доходов бюджетов всех уровней, но и стимулирование роста и развития социально значимых субъектов экономики, к которым относится малый и средний бизнес.

Критерии соответствия субъектам малого и среднего предпринимательства определены ФЗ № 209 от 24 июля 2007 г. «О развитии малого и среднего предпринимательства в Российской Федерации» и Постановлением Правительства РФ от 4 апреля 2016 № 265 «О предельных значениях дохода, полученного от осуществления предпринимательской деятельности, для каждой категории субъектов малого и среднего предпринимательства». К субъектам малого и среднего бизнеса относятся хозяйственные общества, хозяйственные партнерства, производственные кооперати- вы, потребительские кооперативы, крестьянские (фермерские) хозяйства и индивидуальные предприниматели, соответствующие указанным условиям.

По данным Федеральной службы государственной статистики (Росстат), по состоянию на конец 2016 года, в Российской Федерации было зарегистрировано 5307,4 тыс. субъектов малого и среднего предпринимательства (МСП), на которых было занято более 16 млн. человек (табл. 2).

В России достаточно давно признана необходимость развития малого бизнеса, однако Российская Федерация значительно уступает в этом вопросе многим развитым странам. В странах Европейского союза и в США сектор малого и среднего бизнеса выступает основой экономики. По данным $\mathrm{OOH}$, на малых и средних предприятиях в мире занято около 50\% трудового населения и производится от 33\% до 60\% национального продукта. Согласно мировому рейтин-

\section{Таблица 1. Условия отнесения к субъектам малого и среднего предпринимательства}

\begin{tabular}{|c|c|c|c|}
\hline Критерии & $\begin{array}{c}\text { Микро- } \\
\text { предприятия }\end{array}$ & $\begin{array}{c}\text { Малые } \\
\text { предприятия }\end{array}$ & $\begin{array}{c}\text { Средние } \\
\text { предприятия }\end{array}$ \\
\hline $\begin{array}{l}\text { Среднесписочная численность работников за предше- } \\
\text { ствующий календарный год }\end{array}$ & до 15 человек & $\begin{array}{l}\text { от } 16 \text { до } 100 \\
\text { человек }\end{array}$ & $\begin{array}{l}\text { от } 101 \text { до } 250 \\
\text { человек }\end{array}$ \\
\hline $\begin{array}{l}\text { Предельные значения дохода, полученного от осущест- } \\
\text { вления предпринимательской деятельности за предше- } \\
\text { ствующий календарный год }\end{array}$ & до 120 млн. руб. & до 800 млн. руб. & до 2 млрд. руб. \\
\hline $\begin{array}{l}\text { Суммарная доля участия Российской Федерации, субъ- } \\
\text { ектов Российской Федерации, муниципальных обра- } \\
\text { зований, общественных и религиозных организаций } \\
\text { (объединений), благотворительных и иных фондов,\% }\end{array}$ & 25 & 25 & 25 \\
\hline $\begin{array}{l}\text { Суммарная доля участия иностранных юридических лиц } \\
\text { и (или) юридических лиц, не являющихся субъектами } \\
\text { МСП,\% }\end{array}$ & 49 & 49 & 49 \\
\hline
\end{tabular}


Таблица 2. Основные показатели деятельность субъектов МСП в Российской Федерации за 2014-2016 гг.

\begin{tabular}{|c|c|c|c|}
\hline & 2014 г. & 2015 г. & 2016 г. \\
\hline \multicolumn{4}{|l|}{ Средние предприятия } \\
\hline Количество предприятий, тыс. ед. & 13,7 & 19,3 & 13,3 \\
\hline Оборот предприятий, млрд. руб. & 5027,8 & 10362,7 & 7590,4 \\
\hline $\begin{array}{l}\text { Средняя численность работников (без внешних совместителей), } \\
\text { тыс.чел. }\end{array}$ & 1585,8 & 2036,6 & 1676,6 \\
\hline Рентабельность проданных товаров, продукции (работ, услуг),\% & 4,6 & 5,9 & 5,8 \\
\hline \multicolumn{4}{|l|}{ Малые предприятия } \\
\hline Количество предприятий, тыс. ед. & 235,6 & 232,34 & 172,9 \\
\hline Оборот предприятий, млрд. руб. & 16692,9 & 25527,3 & 18738,2 \\
\hline $\begin{array}{l}\text { Средняя численность работников (без внешних совместителей), } \\
\text { тыс.чел. }\end{array}$ & 6358,4 & 6179,7 & 5050,2 \\
\hline Рентабельность проданных товаров, продукции (работ, услуг),\% & 5,3 & 5,2 & 5,0 \\
\hline \multicolumn{4}{|l|}{ Микропредприятия } \\
\hline Количество предприятий, тыс. ед. & 1888,2 & 1990,0 & 2597,6 \\
\hline Оборот предприятий, млрд. руб. & 9699,3 & 18587,0 & 20138,8 \\
\hline $\begin{array}{l}\text { Средняя численность работников (без внешних совместителей), } \\
\text { тыс.чел. }\end{array}$ & 4431,1 & 4197,9 & 5005,7 \\
\hline Рентабельность проданных товаров, продукции (работ, услуг),\% & 5,3 & 5,2 & 5,0 \\
\hline \multicolumn{4}{|l|}{ Индивидуальные предприниматели } \\
\hline $\begin{array}{l}\text { Численность фактически действующих индивидуальных пред- } \\
\text { принимателей тыс. ед. }\end{array}$ & 2413,8 & - & 2523,6 \\
\hline $\begin{array}{l}\text { Объем выручки (с учетом налогов и аналогичных обязательных } \\
\text { платежей) }\end{array}$ & 10447,5 & - & 12369,2 \\
\hline Численность наемных работников & 2435,7 & - & 2469,3 \\
\hline
\end{tabular}

Источник. Составлено по официальным данным Федеральной службы государственной статистики - http://www.gks.ru/.

гу Doing Business 2014, ежегодно составляемый Всемирным банком, на первом месте по благоприятности условий для предпринимательства стоит Сингапур. На 2015 год малые и средние предприятия Сингапура составляют 99\% всех предприятий, а также обеспечивают рабочими местами 70\% всего занятого населения страны. И соответственно половина ВВП приходится на малый бизнес. В этом же рейтинге 4 место занимает США. Здесь больше половины ВВП приходится на малый бизнес, и более половины трудоспособного населения обеспечивается малым бизнесом. Стоит отметить, что малый бизнес занимает сравнительно небольшую долю в экономике России [3].

Система налоговых льгот, предусмотренных для малого бизнеса в странах с развитой экономикой, очень разнообразна и предусматривает различные аспекты налогообложения - снижение ставки подоходного налога, продажу лицензии - патента (замена местных налогов и сборов), упрощение бухгалтерского и налогового учета, предоставление налогового кредита и налоговых каникул.

В соответствии со ст.7 Ф3 N209 от 24.07.2007 [1] мерами нормативно-правового регулирования развития малого и среднего предпринимательства в Российской Федерации являются применение специальных налоговых режимов, упрощенные правила ведения налогового учета, упрощенные формы налоговых деклараций по отдельным налогам и сборам для малых предприятий.

Налоговым кодексом Российской Федерации установлены следующие специальные налоговые режимы:

1) система налогообложения для сельскохозяйственных товаропроизводителей (единый сельскохозяйственный налог);

2) упрощенная система налогообложения;

3) система налогообложения в виде единого налога на вмененный доход для отдельных видов деятельности;

4) система налогообложения при выполнении соглашений о разделе продукции;

5) патентная система налогообложения. 
Таблица 3. Основные показатели налоговой базы по специальным налоговым режимам, применяемым субъектами МСП

\begin{tabular}{|c|c|c|c|c|c|c|}
\hline \multirow[t]{2}{*}{ Наименование } & \multirow[t]{2}{*}{2015 г. } & \multirow[t]{2}{*}{2016 г. } & \multirow[t]{2}{*}{2017 г. } & \multicolumn{3}{|c|}{$\begin{array}{c}\text { Темпы роста, } \\
\text { \% к предыдущему году }\end{array}$} \\
\hline & & & & 2015 г. & 2016 г. & 2017 г. \\
\hline \multicolumn{7}{|l|}{$\begin{array}{l}\text { Единый налог, уплачиваемый в } \\
\text { связи с применением упрощен- } \\
\text { ной системы налогообложения }\end{array}$} \\
\hline $\begin{array}{l}\text { Количество налогоплательщиков, } \\
\text { сдающих декларацию по налогу, } \\
\text { уплачиваемому в связи с приме- } \\
\text { нением УСН (единиц) }\end{array}$ & 2818063 & 2874817,0 & 3056467 & 112,2 & 102,0 & 106,3 \\
\hline \multicolumn{7}{|l|}{ Налоговая база, в том числе: } \\
\hline доходы (млн. руб.) & 4397158,7 & 4833977,2 & 5870528,5 & 114,5 & 109,9 & 121,4 \\
\hline $\begin{array}{l}\text { доходы, уменьшенные на вели- } \\
\text { чину расходов (млн. руб.) }\end{array}$ & 530218,4 & 636938,3 & 813092,3 & 116,5 & 120,1 & 127,7 \\
\hline $\begin{array}{l}\text { Сумма налога, подлежащая упла- } \\
\text { те (млн. руб.), в том числе: }\end{array}$ & 236008,1 & 259003,3 & 320057,9 & 113,7 & 109,7 & 123,6 \\
\hline налога с доходов (млн. руб.) & 182278,8 & 196167,3 & 241360,0 & 114,2 & 107,6 & 123,0 \\
\hline $\begin{array}{l}\text { налога с доходов, уменьшенных } \\
\text { на величину расходов (млн. } \\
\text { руб.) }\end{array}$ & 53729,3 & 62836,0 & 78697,9 & 112,2 & 116,9 & 125,2 \\
\hline $\begin{array}{l}\text { Сумма минимального налога, } \\
\text { подлежащая уплате (млн. руб.) }\end{array}$ & 22560,1 & 26079,4 & 30373,6 & 114,6 & 115,6 & 116,5 \\
\hline \multicolumn{7}{|l|}{$\begin{array}{l}\text { Единый налог на вмененный } \\
\text { доход для отдельных видов дея- } \\
\text { тельности }\end{array}$} \\
\hline $\begin{array}{l}\text { Количество налогоплательщиков } \\
\text { (единиц) }\end{array}$ & 2094253 & 2033504 & 2044154 & 97,7 & 97,1 & 100,5 \\
\hline $\begin{array}{l}\text { Налоговая база (сумма исчислен- } \\
\text { ного вмененного дохода) (млн. } \\
\text { руб.) }\end{array}$ & 951369,6 & 894342,2 & 892178,9 & 104,9 & 94,3 & 99,8 \\
\hline $\begin{array}{l}\text { Сумма единого налога на вме- } \\
\text { ненный доход, подлежащая } \\
\text { уплате за налоговый период } \\
\text { (млн. руб.) }\end{array}$ & 79162,4 & 72522,8 & 69869,9 & 102,6 & 92,2 & 96,3 \\
\hline \multicolumn{7}{|l|}{$\begin{array}{l}\text { Единый сельскохозяйственный } \\
\text { налог }\end{array}$} \\
\hline $\begin{array}{l}\text { Количество налогоплательщиков } \\
\text { (единиц) }\end{array}$ & 98310 & 99716 & 100712 & 104,6 & 101,4 & 101,0 \\
\hline Налоговая база (млн. руб.) & 195838,5 & 212471,7 & 206644,4 & 161,3 & 108,5 & 97,3 \\
\hline $\begin{array}{l}\text { Сумма исчисленного единого } \\
\text { сельскохозяйственного налога } \\
\text { (млн. руб.) }\end{array}$ & 9586,6 & 11367,5 & 11193,8 & 175,8 & 118,6 & 98,5 \\
\hline \multicolumn{7}{|l|}{$\begin{array}{l}\text { Патентная система налогообло- } \\
\text { жения }\end{array}$} \\
\hline $\begin{array}{l}\text { Количество ИП, применяющих } \\
\text { ПСН (единиц) }\end{array}$ & 241135 & 243671 & 287766 & 243,5 & 133,7 & 118,1 \\
\hline $\begin{array}{l}\text { Количество выданных патентов } \\
\text { (единиц) }\end{array}$ & 182198 & 321606 & 383256 & 149,2 & 133,4 & 119,2 \\
\hline
\end{tabular}

Источник. Составлено по официальным данным ФНС РФ- https://nalog.ru.

При этом система налогообложения при выполнении соглашений о разделе продукции не предназначена для субъектов малого и среднего бизнеса. Стоит отметить, что патентная система налогообложения предусмотрена только для ин- дивидуальных предпринимателей.

На основе данных табл. 3, можно сделать вывод о том, что наибольшей популярностью пользуется упрощенная система налогообложения. Очевидно, что рост налоговой базы и суммы 
Таблица 4. Поступления налоговых доходов по специальным налоговым режимам в структуре консолидированного бюджета РФ

\begin{tabular}{|l|c|c|c|c|c|c|}
\hline \multicolumn{1}{|c|}{ Наименование } & \multicolumn{3}{|c|}{2016 г. } & \multicolumn{2}{c|}{2017 г. } \\
\cline { 2 - 7 } & $\begin{array}{c}\text { Всего, } \\
\text { млн.руб. }\end{array}$ & $\begin{array}{c}\text { В \% к } \\
2015 \text { г. }\end{array}$ & Уд. вес (\%) & $\begin{array}{c}\text { Всего, } \\
\text { млн.руб. }\end{array}$ & В \% 2016 г. & Уд. вес (\%) \\
\hline $\begin{array}{l}\text { Единый налог, взимаемый в связи } \\
\text { с применением упрощенной } \\
\text { системы налогобложения }\end{array}$ & 287053,2 & 112,9 & 2,0 & 345201,0 & 120,3 & 2,0 \\
\hline $\begin{array}{l}\text { Единый налог на вмененный } \\
\text { доход для отдельных видов дея- } \\
\text { тельности }\end{array}$ & 74320,0 & 94,7 & 0,5 & 70625,4 & 95,0 & 0,4 \\
\hline $\begin{array}{l}\text { Единый сельскохозяйственный } \\
\text { налог }\end{array}$ & 11436,4 & 153,9 & 0,1 & 11890,4 & 104,0 & 0,1 \\
\hline
\end{tabular}

Составлено по официальным данным ФНС РФ - https://nalog.ru.

налога, подлежащей уплате в бюджет по упрощенной системе налогообложения, опережают рост количества налогоплательщиков, сдающих декларацию по данному налогу.

В частности положительная динамика наблюдается по обоим объектам налогообложения УСН - с дохода и с доходов, уменьшенных на сумму расходов.

Налоговые поступления от применения ЕНВД за рассматриваемый период уменьшились. Однако отрицательная динамика по основным показателям в 2017 г. заметно снизилась (табл.4). При этом увеличилось и количество налогоплательщиков ЕНВД.

Налоговые доходы от ЕСХН незначительны, но потенциал этого режима высокий. Если усовершенствовать данный специальный режим, то это позволит перейти успешным сельскохозяйственным производителям на эту систему налогообложения.

Экономическая эффективность малых предприятий во многом зависит от государственной политики, направленной как на создание условий и предоставление различных преференций для его развития, так и поддержки в период экономического кризиса, последствия которых в этом секторе народного хозяйства наиболее тяжелые. Активизация стимулирующей функции налогов должна сопровождаться упрощением и стабильностью налогообложения, а ее социальная ориентация снизит негативные последствия экономического кризиса. Результатом преобразований должна стать заинтересованность представителей малого и среднего предпринимательства в увеличении доходов, создании рабочих мест, и как следствие создание дополнительных источников доходов бюджетов разных уровней.
Существующие в настоящее время специальные режимы налогообложения не позволяют в полной мере развиваться малому бизнесу, так как наращивание производственных мощностей и доходов приводит к потере права на использование льготного налогообложения.

При анализе специальных налоговых режимов можно сделать общий вывод, который заключается в том, что для повышения объёма бюджетных доходов по специальным налоговым режимам необходимо пересмотреть и усовершенствовать законодательную базу. В первую очередь требуют изменений условия, в соответствии с которыми организации и предприниматели способны перейти на данные режимы. Так как специальные режимы предназначены в большей части для поддержки малого бизнеса, поэтому они должны содействовать развитию и наращиванию масштабов деятельности субъектов МСП, а не сдерживать темпы их роста. В целях повышения эффективности системы специальных режимов налогообложения необходимо их реформирование.

Для системы единого сельскохозяйственного налога (ЕСХН).

Предоставить право сельхозтоваропроизводителям в добровольном порядке регистрироваться в качестве плательщиков НДС, что позволит им воспользоваться правом налогового вычета по уплаченному НДС при приобретении горюче-смазочных материалов, удобрений, кормов, оплате услуг сторонних организаций после реализации своей продукции. Данная мера позволит снизить затраты сельхозпроизводителей и расширить список контрагентов, которые являются плательщиками данного налога. 
Для упрощенной системы налогообложения (УCH).

1. Установить максимальный показатель годового дохода для налогоплательщиков УСН в соответствие со значениями, установленными в Постановлении Правительства РФ для малых и средних предприятий,- 800 млн. руб. Приведение предельного показателя дохода по УСН позволит предприятиям малого бизнеса воспользоваться данной системой налогообложения, будет способствовать росту их реального количества, сокращению их искусственного прироста за счет дробления бизнеса в целях применения УСН. При этом данная поправка будет способствовать росту оборота малого бизнеса, не ограничивая их рамками (150 млн.руб.).

2. Упразднить ограничения по остаточной стоимости основных средств в размере 150 млн. руб. Данная норма оказывает отрицательное воздействие на развитие малого бизнеса, не позволяя обновлять парк основных средств.

3. Предоставить налогоплательщикам возможность право выставления счета-фактуры и учета входного НДС. Данная льгота позволит не только снизить затраты, но и увеличить реализацию товаров за счет привлечения контрагентов-плательщиков НДС.
Для системы налогообложения в виде уплаты единого налога на вмененный доход для отдельных видов деятельности (ЕНВД).

1. Возможности данного режима налогообложения как метода стимулирования снижения теневой деятельности, далеко не исчерпаны, несмотря на невысокий уровень поступлений от применения данного налогового режима. В виду значительных территориальных различий в экономических условиях, необходимо более широко применять указанный налоговый режим, расширив состав налогоплательщиков в разрезе видов экономической деятельности [4].

2. Расширить диапазон установления значений корректирующего коэффициента К2 до 2-х для высокорентабельных видов деятельности.

Для патентной системы налогообложения (ПСН).

1. Целесообразно предусмотреть различные уровни налоговых ставок для бизнеса, функционирующего в сфере услуг и производства.

2. Предоставить возможность снижения стоимости патента за счет уплаченных страховых взносов, по аналогии с упрощенной системой налогообложения и единым налогом на вмененный доход.

\section{Библиографический список}

1. Федеральный закон от 24 июля 2007 г. № 209-ФЗ «О развитии малого и среднего предпринимательства в Российской Федерации».

2. Постановление Правительства РФ от 4 апреля 2016 № 265 «О предельных значениях дохода, полученного от осуществления предпринимательской деятельности, для каждой категории субъектов малого и среднего предпринимательства».

3. Кван M.Е. Эффективность применения специальных налоговых режимов субъектами малого предпринимательства/ Кван М.Е.// Экономика и предпринимательство. 2017. № 3-2 (80). С. 546-550.

4. Осадчук Л.М., Осадчук М.С. Специальные налоговые режимы как инструмент стимулирования предпринимательской деятельности в регионе/ Осадчук Л.М., Осадчук М.С.// Экономика и предпринимательство. 2018. № 1 (90). С. 315-318. 